\title{
Major decline in malaria morbidity and mortality in the Union of Comoros between 2010 and 2014: The effect of a combination of prevention and control measures
}

\author{
S A Kassim, ${ }^{1,4} \mathrm{PhD}$; P B James, ${ }^{2} \mathrm{MSc}$; R N Alolga, ${ }^{3} \mathrm{PhD}$; A G Assanhou, ${ }^{3} \mathrm{PhD}$; S M Kassim, ${ }^{4} \mathrm{MD} ;$ A Bacar, ${ }^{5} \mathrm{MD} ; \mathbf{R}$ Silai, ${ }^{5} \mathrm{MSc}$; \\ L Tian, ${ }^{1} \mathrm{MSc} ; \mathbf{H ~ L i},{ }^{1} \mathrm{PhD} ; \mathbf{A ~ M a},{ }^{1} \mathrm{PhD}$ \\ ${ }^{1}$ School of International Economics and Trade, China Pharmaceutical University, Nanjing, China \\ ${ }^{2}$ Department of Social and Administrative Pharmacy, School of International Economics and Trade, China Pharmaceutical University, \\ Nanjing, China \\ ${ }^{3}$ School of Pharmacy, China Pharmaceutical University, Nanjing, China \\ ${ }^{4}$ Department of Internal Medicine - Gastroenterology, Southern Medical University, Guangzhou, China \\ ${ }^{5}$ National Malaria Control Center, Ministry of Health, Moroni, Comoros
}

Corresponding author: A Ma (maaixia@cpu.edu.cn)

Background. Malaria remains a public health challenge in sub-Saharan Africa. In response to this, many countries are working towards achieving the World Health Assembly and Roll Back Malaria Partnership target of a 75\% decline in malaria incidence.

Objective. To assess trends in malaria morbidity and mortality in the three islands of the Comoros Archipelago from 2010 to 2014 .

Methods. This was a retrospective study in which all confirmed malaria cases and deaths recorded between 2010 and 2014 were accessed from the national malaria control database. Trends and comparisons in malaria incidence and case fatality rates for all age groups, including under-5 children and pregnant women, were analysed using Microsoft Excel and SPSS version 16.

Results. A substantial decline in malaria incidence was observed for each island between 2010 and 2014; from 75.98 cases per 1000 population in 2010 to 0.14 in 2014 in Moheli, 60.60 to 0.02 in Anjouan and 235.36 to 5.47 in Grand Comoro. Additionally, a general reduction in malaria case fatalities was observed. In Moheli, there were no case fatalities between 2010 and 2014, while there was a decline in the case fatality rate in Anjouan (from 1.20 fatalities per 1000 cases to 0 ) and Grand Comoros ( 0.51 to 0$)$. There were also significant differences $(p<0.05)$ in malaria incidence and case fatalities between the three islands. A similar trend was observed for pregnant women and under-5 children.

Conclusion. Our study indicates a significant decline in malaria morbidity and mortality in the islands of Moheli, Anjouan and Grand Comoro from 2010 to 2014. This considerable reduction is attributed to a combination of malaria prevention and control interventions implemented during the study period.

S Afr Med J 2016;106(7):709-714. DOI:10.7196/SAMJ.2016.v106i7.10902

Despite progress over the century in the global eradication of malaria, the disease still remains a public health challenge, especially in sub-Saharan Africa. In this region, there were 163 million malaria cases and 528000 deaths from malaria in 2013. ${ }^{[1]}$ Nevertheless, the past decade has witnessed a reduction in malaria morbidity and mortality. For example, $34 \%$ and $54 \%$ decreases in malaria incidence and deaths were recorded respectively between 2000 and 2013. This decline is attributed to increased funding, which has led to scaling up of current malaria prevention and control interventions, i.e. expanded distributions, use and coverage of vector control strategies such as of insecticide-treated bed nets (ITNs) and indoor residual spraying (IRS), increased use of rapid diagnostic tests (RDTs) for prompt diagnosis and increased access to malaria case management using artemisinin-combination therapy (ACT). ${ }^{[1]}$ For example, malaria spending has increased threefold since 2005, and nearly $50 \%$ of the at-risk population had access to ITNs in 2013, compared with 7\% in 2004. Increased access to RDTs and quality ACT was also observed on the continent. ${ }^{[1]}$ Additionally, climate change, increased land use for agriculture and housing, as well as urbanisation, have been posited as contributing factors to the observed decline..$^{[2,3]}$ Notwithstanding these remarkable achievements, most African countries are way behind in achieving the World Health Assembly and Roll Back Malaria Partnership target of a 75\% decline in malaria

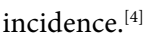

The Comoros Archipelago is located in the Indian Ocean between Madagascar and the eastern coast of Africa. Its projected population for 2012 was 718000 inhabitants, and it had an annual population growth rate of $2.4 \%$ between 2010 and 2015. It consists of four islands: Mayotte, Moheli, Anjouan and Grand Comoro, with the last three collectively called the Union of Comoros. ${ }^{[5]}$ It has a tropical climate with a wet and humid season from November to April/May and a dry season from May to October. Ninety-six percent of all malaria infections in Comoros are due to the parasite species Plasmodium falciparum and the local vector is predominantly Anopheles gambiae. Malaria, which is endemic in that part of Africa, is transmitted mainly during the rainy season although the level of malaria endemicity varies greatly from one island to the other. ${ }^{[6]}$

Since independence, the Comoros Archipelago has implemented an evidence-based malaria control policy, with chloroquine being the main drug for malaria treatment and prophylaxis. This was in line with the World Health Organization (WHO)'s strategy for malaria control at that time. ${ }^{[7]}$ The desired outcome of this control measure was not achieved prior to 2004 because of political instability and budgetary constraints at that time coupled with the emergence of resistance to chloroquine. ${ }^{[8,9]}$ In 2003, the Comoros government, with support from its international partners, implemented the use of arthemetherlumefantrine as a malaria treatment policy change. ${ }^{[7]}$ In 2004, other malaria control interventions were started, such as IRS, mass 
distribution of ITNs/long-lasting insecticide nets (LLINs), intermittent prevention therapy for pregnant women (IPTp), and diagnosis and treatment of malaria cases. The IPTp intervention was adopted in 2004, while in 2005 free distribution of mosquito nets only targeted pregnant and under- 5 children (U5C); this was rolled out to all age groups in 2010. IRS was also started in 2010. ${ }^{[4]}$ The malaria diagnosis policy was adopted from 1997 but was not fully implemented until 2011 when it was made freely available in all public hospitals and clinics. ${ }^{[10]}$ Although arthemether-lumefantrine was adopted as first-line drug therapy for uncomplicated malaria in 2003, free access for the general population in public health facilities only came into effect in $2010 .{ }^{[4]}$ Data on the coverage of most of these interventions were scanty, especially before 2010. However, recent Demographic Health Survey reports revealed that slightly over and below $40 \%$ of the population of Comoros had access to ITNs and slept under one, respectively. ${ }^{[11]}$ In addition, less than $10 \%$ of the at-risk population had IRS for malaria prevention between 2010 and 2011. In 2007, fast elimination of malaria by source eradication (FEMSE) was adopted in addition to existing malaria control interventions. This began in 2007 in Moheli, 2012 in Anjouan and 2013 in Grand Comoro. The FEMSE intervention is a method of mass drug administration (MDA) with artemisinin-piperaquine and primaquine. It is aimed at completely removing mosquito parasites in the human body as well as preventing reinfection by mosquitoes, thereby blocking the spread of malaria. ${ }^{[12]}$ This method had successfully achieved a substantial reduction in malaria prevalence outside Africa, ${ }^{[13]}$ creating renewed interest in MDA as a potential elimination strategy for malaria. However, evidence of its success in the African region remains limited. ${ }^{[14]}$

Lack of sufficient financing, poor public health infrastructure, limited skilled human capacity, poor quality health services and commodities in the private sector, threat of resistance to life-saving ACTs and lack of intersectoral collaboration have been put forward as potential barriers to scaling up malaria control intervention in developing nations. ${ }^{[15]}$ These challenges have raised concerns as to whether the Roll Back Malaria partnership target will be met in 2015. ${ }^{[4]}$ Despite these challenges, some African countries, including South Africa, Rwanda, Ethiopia, Zambia and Zimbabwe, are on course to achieve the targets. ${ }^{[4]}$ In addition, a recent study in the nearby island of Mayotte ${ }^{[16]}$ indicated a decline in malaria incidence and deaths. Similar patterns have
Table 1. Malaria incidence rate and CFR for all ages, 2010 - 2014

\begin{tabular}{lllllll}
\hline \multirow{5}{*}{ Island } & Year & Cases, $\boldsymbol{n}$ & $\begin{array}{l}\text { Cases per } \\
\text { month, mean }\end{array}$ & $\begin{array}{l}\text { Incidence rate } \\
\text { (cases per 1 000 } \\
\text { population) }\end{array}$ & Deaths, $\boldsymbol{n}$ & $\begin{array}{l}\text { CFR (deaths } \\
\text { per 1 000 } \\
\text { cases) }\end{array}$ \\
\hline Moheli & 2010 & 3420 & 285.00 & 75.98 & 0 & 0 \\
& 2011 & 1952 & 162.67 & 42.11 & 0 & 0 \\
& 2012 & 842 & 70.17 & 17.66 & 0 & 0 \\
& 2013 & 83 & 6.92 & 1.68 & 0 & 0 \\
& 2014 & 7 & 0.58 & 0.14 & 0 & 0 \\
Anjouan & 2010 & 17638 & 147.00 & 60.60 & 10 & 0.57 \\
& 2011 & 9973 & 509.25 & 33.38 & 12 & 1.20 \\
& 2012 & 4042 & 335.33 & 13.11 & 4 & 0.99 \\
& 2013 & 67 & 5.58 & 0.21 & 1 & 14.93 \\
Grand & 2014 & 5 & 0.42 & 0.02 & 0 & 0 \\
Comoro & 2010 & 82612 & 6884.30 & 235.36 & 42 & 0.51 \\
& 2011 & 64732 & 4811.30 & 179.81 & 41 & 0.63 \\
& 2012 & 60297 & 5023.20 & 163.11 & 13 & 0.22 \\
& 2013 & 53979 & 4498.20 & 142.30 & 14 & 6.57 \\
& 2014 & 2130 & 177.50 & 5.47 & 0 & 0
\end{tabular}

Table 2. Comparison of malaria cases and deaths between the three islands for all ages, 2010 - 2014

\begin{tabular}{lllll}
\hline Island & $\begin{array}{l}\text { Malaria cases per } \\
\text { year, mean }\end{array}$ & $\boldsymbol{p}$-value & $\begin{array}{l}\text { Deaths per } \\
\text { year, mean }\end{array}$ & $\boldsymbol{p}$-value \\
\hline Moheli & 1260.80 & 0.001 & 0 & 0.023 \\
Anjouan & 6341.40 & & 5.40 & \\
Grand Comoro & 52750.80 & & 22.00 &
\end{tabular}

Table 3. Malaria incidence rate and CFR for pregnant women, 2010 - 2014

\begin{tabular}{|c|c|c|c|c|c|c|}
\hline Island & Year & Cases, $n$ & $\begin{array}{l}\text { Cases per } \\
\text { month, mean }\end{array}$ & $\begin{array}{l}\text { Incidence rate } \\
\text { (cases per } 1000 \\
\text { pregnant women) }\end{array}$ & Deaths, $n$ & $\begin{array}{l}\text { CFR (deaths } \\
\text { per } 1000 \\
\text { pregnant } \\
\text { women) }\end{array}$ \\
\hline \multirow[t]{5}{*}{ Moheli } & 2010 & 60 & 5.00 & 38.05 & 0 & 0 \\
\hline & 2011 & 22 & 1.67 & 13.53 & 0 & 0 \\
\hline & 2012 & 2 & 0.17 & 1.19 & 0 & 0 \\
\hline & 2013 & 2 & 0.17 & 1.16 & 0 & 0 \\
\hline & 2014 & 1 & 0.08 & 0.56 & 0 & 0 \\
\hline \multirow[t]{5}{*}{ Anjouan } & 2010 & 1278 & 106.50 & 125.52 & 3 & 2.35 \\
\hline & 2011 & 453 & 37.75 & 43.32 & 4 & 8.83 \\
\hline & 2012 & 40 & 3.33 & 3.72 & 1 & 25.00 \\
\hline & 2013 & 3 & 0.25 & 0.27 & 0 & 0 \\
\hline & 2014 & 0 & 0 & 0 & 0 & 0 \\
\hline Grand & 2010 & 2368 & 197.33 & 192.83 & 10 & 4.22 \\
\hline \multirow[t]{4}{*}{ Comoro } & 2011 & 1614 & 134.50 & 128.06 & 11 & 6.82 \\
\hline & 2012 & 1430 & 191.17 & 110.35 & 2 & 1.40 \\
\hline & 2013 & 1150 & 95.83 & 86.62 & 5 & 4.35 \\
\hline & 2014 & 93 & 7.75 & 6.83 & 0 & 0 \\
\hline
\end{tabular}


been reported in Rwanda and Tanzania, ${ }^{[17,18]}$ while the opposite was observed in Togo. ${ }^{[19]}$ However, there is paucity of published malaria data on the other three islands of Comoros Archipelago (Moheli, Anjouan and Grand Comoro). These three islands are unique as, compared with Mayotte, they do not receive support from France and the national malaria control programme has full authority. They have also experienced political upheaval in recent times that has affected socioeconomic activities. ${ }^{[9]}$ Since 2010, the WHO malaria case management guidelines, which emphasise malaria case confirmation before initiation of treatment, have been implemented in all three islands. ${ }^{[4]}$ Therefore, it important to assess how these islands have performed since 2010 in their quest to eliminate malaria. It is against this background that we decided to conduct this study, with the aim of assessing trends in malaria morbidity and mortality after the combined intervention of malaria control tools (IRS, ITNs, IPTp, etc.) and the FEMSE strategy were implemented in the three islands.

\section{Methods}

\section{Study design, time period and ethical clearance}

This was a retrospective cross-sectional study carried out in the three islands of Moheli, Anjouan and Grand Comoro from 2010 to 2014. The regional office of the national malaria control programme in each island collected malaria data from each public and private health facility on a monthly basis and these were sent to headquarters in Grand Comoro for analysis. Ethical clearance for the study was obtained from the Ministry of Health of the Comoros.

\section{Study setting}

The Union of Comoros covers an area of $2300 \mathrm{~km}^{2}$ with a total population of 734000 and population growth rate (2010 - 2015) of $2.4 \%$. Moheli covers an area of $211 \mathrm{~km}^{2}$ and represents $6 \%$ of the total population. Anjouan island has a total area of $424 \mathrm{~km}^{2}$ and represents $42 \%$ of the total population while the island of Grand Comoro, which covers an area of $1025 \mathrm{~km}^{2}$, represents $52 \%$ of the total population of the country. ${ }^{[20]}$

\section{Source of epidemiological data}

Data were sourced from the national malaria control programme database. The end of political instability in these three islands in $2008^{[9]}$ led to the development of a new malaria treatment policy in 2010 that ensures free access to malaria treatment to all age groups in both public and private

Table 4. Comparison of malaria cases and deaths between the three islands for pregnant women, 2010 - 2014

\begin{tabular}{|c|c|c|c|c|}
\hline Island & $\begin{array}{l}\text { Malaria cases in pregnant } \\
\text { women per year, mean }\end{array}$ & $p$-value & $\begin{array}{l}\text { Malaria deaths in pregnant } \\
\text { women per year, mean }\end{array}$ & $p$-value \\
\hline Moheli & 17.40 & 0.09 & 0 & 0.031 \\
\hline Anjouan & 354.80 & & 1.60 & \\
\hline Grand Comoro & 1331.00 & & 5.60 & \\
\hline
\end{tabular}

Table 5. Malaria incidence rate and CFR for U5C, 2010 - 2014

\begin{tabular}{|c|c|c|c|c|c|c|}
\hline Island & Year & Cases, $n$ & $\begin{array}{l}\text { Cases per } \\
\text { month, mean }\end{array}$ & $\begin{array}{l}\text { Incidence rate } \\
\text { (cases per } 1000 \\
\text { U5C) }\end{array}$ & Deaths, $n$ & $\begin{array}{l}\text { CFR (deaths } \\
\text { per } 1000 \\
\text { U5C) }\end{array}$ \\
\hline \multirow[t]{5}{*}{ Moheli } & 2010 & 702 & 58.50 & 96.82 & 0 & 0 \\
\hline & 2011 & 658 & 54.83 & 88.27 & 0 & 0 \\
\hline & 2012 & 370 & 30.83 & 48.28 & 0 & 0 \\
\hline & 2013 & 12 & 1.00 & 1.52 & 0 & 0 \\
\hline & 2014 & 1 & 0.08 & 0.12 & 0 & 0 \\
\hline \multirow[t]{5}{*}{ Anjouan } & 2010 & 6867 & 572.25 & 147.51 & 6 & 0.87 \\
\hline & 2011 & 2532 & 211.00 & 52.96 & 5 & 1.97 \\
\hline & 2012 & 1164 & 89.50 & 23.71 & 3 & 2.58 \\
\hline & 2013 & 5 & 0.42 & 0.10 & 1 & 200.00 \\
\hline & 2014 & 1 & 0.08 & 0.02 & 0 & 0 \\
\hline \multirow{5}{*}{$\begin{array}{l}\text { Grand } \\
\text { Comoro }\end{array}$} & 2010 & 30960 & 2580.00 & 551.63 & 21 & 0.68 \\
\hline & 2011 & 26881 & 2240.08 & 466.62 & 10 & 0.37 \\
\hline & 2012 & 21882 & 1818.60 & 369.05 & 9 & 0.41 \\
\hline & 2013 & 16074 & 1339.50 & 264.05 & 5 & 0.31 \\
\hline & 2014 & 767 & 63.92 & 12.31 & 0 & 0 \\
\hline
\end{tabular}

Table 6. Comparison of malaria cases and deaths in U5C between the islands, 2010 - 2014

\begin{tabular}{|c|c|c|c|c|}
\hline Island & $\begin{array}{l}\text { Malaria cases in U5C } \\
\text { per year, mean }\end{array}$ & $p$-value & $\begin{array}{l}\text { Malaria deaths in U5C } \\
\text { per year, mean }\end{array}$ & $p$-value \\
\hline Moheli & 348.60 & 0.002 & 0 & 0.031 \\
\hline Anjouan & 2113.80 & & 3.00 & \\
\hline Grand Comoro & 19312.8 & & 9.00 & \\
\hline
\end{tabular}

health facilities. ${ }^{[10]}$ This provided the opportunity for details of each malaria case reported to health facilities to be recorded on a case notification form. Cases were treated at health facilities as per the WHO guidelines for malaria case management. ${ }^{[21]}$ Information on deaths due to malaria was collected using the same mechanism. Aggregate data from all health facilities were sent to the malaria control programme office on each island on a monthly basis where preliminary vetting for completeness and accuracy was carried out. These data were then sent to the malaria control programme headquarters in Grand Comoro where they were checked again for completeness, and final analysis was carried out.

\section{Data analysis}

The data collected from the national malaria programme database, which was set up and routinely validated by WHO, were analysed using Microsoft Excel and SPSS version 16 (IBM, USA). Data from 2010 to 2014 for Moheli, Anjouan and Grand Comoro were analysed. Individual-level data were not available, therefore sex distribution could not be analysed. However, aggregated data for targeted groups, i.e. U5C and pregnant women, were present. Malaria incidence was calculated using the projected yearly population for each island sourced from the 2003 population and housing census. Malaria incidence per 1000 people was calculated for each year. Malaria case fatality 


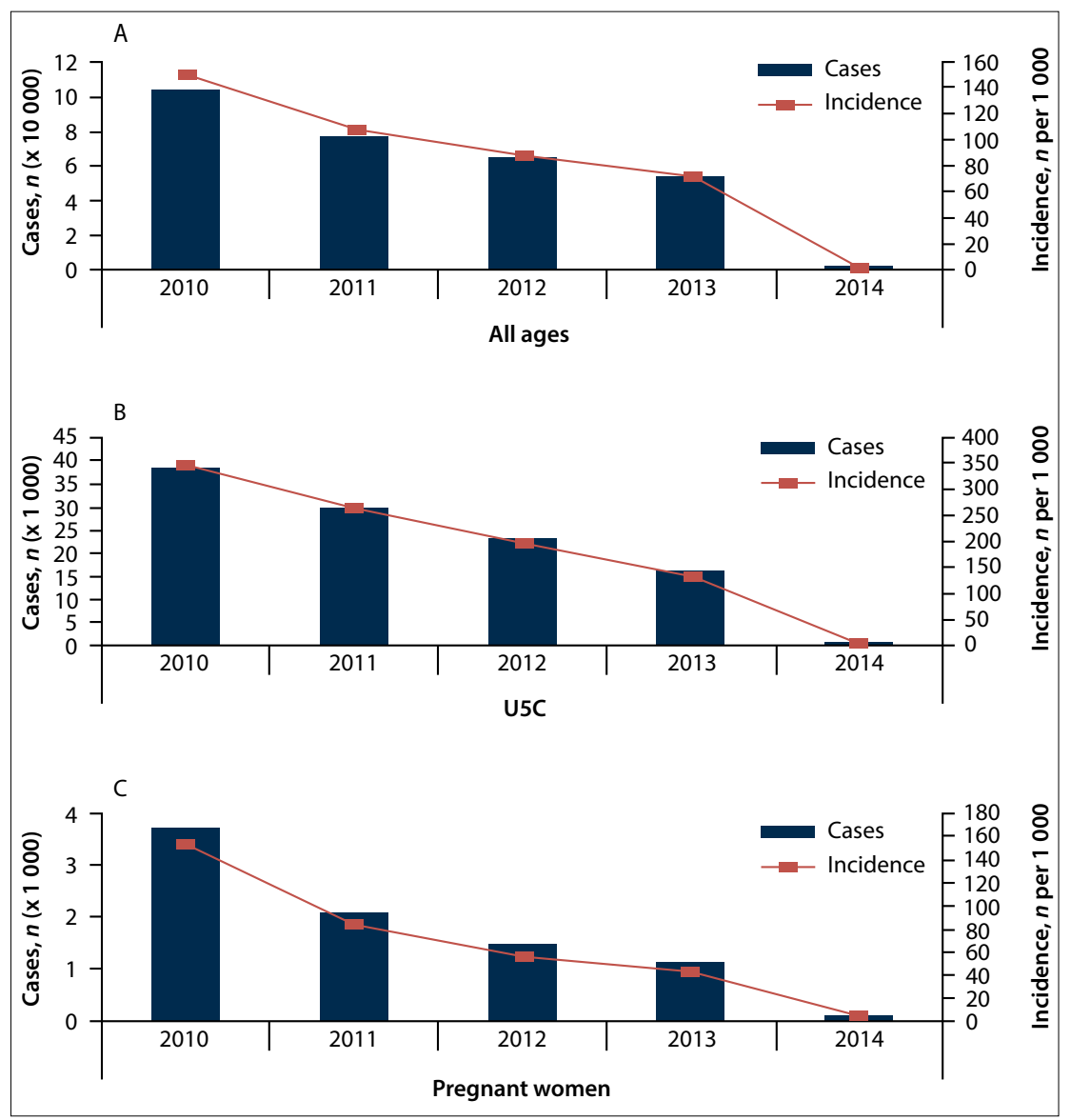

Fig. 1. Trends in number of malaria cases and incidence between 2010 and 2014 for all ages (A), U5C (B) and pregnant women (C) in all three islands.

rate (CFR) was calculated by dividing the number of malaria deaths by the number of malaria cases for that year and the results expressed per 1000 . One-way analysis of variance (ANOVA) was employed to compare the number of malaria cases and deaths between the three islands. $p<0.05$ was considered statistically significant.

\section{Results}

Malaria incidence and case fatalities in all ages, 2010 - 2014

From 2010 to 2014, the total number of malaria cases in all three islands was 301765 , with the mean number of malaria cases per year $1260.80,6341.40$ and 52750.80 in Moheli, Anjouan and Grand Comoro, respectively. A 99\% (from 3420 to 7 cases), $100 \%$ (from 17638 to 5 cases) and 99\% (from 82612 to 2130 cases) reduction in malaria cases was also observed from 2010 to 2014 in Moheli, Anjouan and Grand Comoro, respectively. In addition, a substantial decline in malaria incidence was observed for each island; 75.98 cases per 1000 population to 0.14 in Moheli, 60.60 to 0.02 in Anjouan and 235.36 to 5.47 in Grand Comoro. Furthermore, a general reduction in malaria case fatalities was also observed. In Moheli, there were no case fatalities from 2010 to 2014 , while there was a decline in Anjouan and Grand Comoro. There was a significant difference $(p<0.05)$ in number of malaria cases and case fatalities between the three islands. Tables 1 and 2 provide further details.

\section{Malaria incidence and case fatalities} in pregnant women, 2010 - 2014

In the cohort of pregnant women, Grand Comoro (1 331.00) and Anjouan (354.80) had higher mean cases of malaria per year than Moheli (17.40) A steady decline in malaria incidence in pregnant women from 2010 to 2014 was noticed for all three islands. Incident cases per 1000 pregnant women reduced from 38.05 in 2010 to 0.56 in 2014 in Moheli, 125.52 to 0 in Anjouan and 192.83 to 6.83 in Grand Comoro. No case fatalities in pregnant women were observed in Moheli over the period under review and Anjouan (2.35 to 0 ) and Grand Comoro (4.22 to 0 ). A statistically significant difference was observed for number of deaths due to malaria between the three islands. Tables 3 and 4 provide further details. a reduction in the CFR was observed in

\section{Malaria incidence rate and case fatalities in U5C, 2010 - 2014}

Among U5C, a similar pattern was observed to that of pregnant women. A steady decline in malaria incidence was seen from 2010 to 2014 in Moheli (96.82 cases per 1000 U5C to 0.12 ), Anjouan (147.51 to 0.02 ) and Grand Comoro (551.63 to 12.31). No case fatalities were observed in Moheli, and a general reduction in the U5C CFR was observed in Anjouan (0.87 to 0$)$ and Grand Comoro (0.68 to 0$)$. A statistically significant difference was observed for number of fatalities, but not for number of cases, between the three islands. For further details refer to Tables 5 and 6.

\section{Trends in malaria morbidity and mortality, 2010 - 2014}

For each cohort, there was a gradual decline in the total number of malaria cases and incidence (Fig. 1). Fig. 2A shows no difference in the total number of deaths in 2010 and 2011. This was followed by a significant drop in 2012 which remained similar in 2013. However, a significant reduction was observed for 2014 in which no deaths were reported. Case fatalities show a gradual decline in 2010 to 2012 followed by a large rise in 2013 and large fall in 2014. Fig. 2B presents a gradual decline in both total number of deaths and CFR for U5C whereas Fig. 2C shows an increase in deaths for pregnant women from 2010 to 2011 followed by a fall in 2012 and rise in 2013 and fall to zero figures in 2014. Fig. 3 shows the effect of the implementation of key malaria interventions, including LLINs, ACT MDA and FEMSE, on the number of malaria cases recorded after their implementation. For example, there was a decline in the number of malaria cases after a LLIN intervention was implemented in November 2010 in all three islands. A similar picture was observed following the implementation of ACT MDA in all three islands and FEMSE interventions in Anjouan and Grand Comoro.

\section{Discussion}

The main aim of this article is to present trends in malaria morbidity and mortality in three islands of the Comoros - Moheli, Anjouan and Grand Comoro - from 2010 to 2014. The year 2010 was chosen as it coincided with the implementation of WHO malaria guidelines emphasising the need for confirmation of malaria either through microscopy or RDT before treatment is initiated. This gives credence to all cases and deaths recorded from 2010 being due to malaria. 
In all three islands, an at least $98 \%$ reduction in malaria incidence and case fatalities was observed from 2010 to 2014. This is in line with the WHO country report ${ }^{[22]}$ and similar to the reduction in malaria incidence reported from a study done on the neighbouring island of Mayotte ${ }^{[16]}$ although at different periods. The outcomes of this study correlate with a similar study conducted in Mpumalanga Province, SA, in which an $87 \%$ reduction in malaria incidence was reported ${ }^{[23]}$ and in Tanzania where a $85 \%$ decline in malaria cases was recorded. ${ }^{[17]}$ The outcomes are also similar to those of a study conducted in Cambodia. ${ }^{[13]}$ The difference in figures is probably due to differences in study location, methodologies used and time periods under review. Furthermore, our study was conducted with data from three islands, compared with a single geographical location in the SA and Tanzanian studies. Although the picture was generally similar for all three islands, some differences were observed between them. For example, we observed a significant difference in malaria incidence and CFRs between the three islands, with Grand Comoro having higher incidence and CFRs than the other two islands. Post-hoc analysis indicated no significant difference in incidence and CFR between Moheli and Anjouan but a significant difference existed between these and Grand Comoro. The reasons for this observation are related to population densities in the three islands -
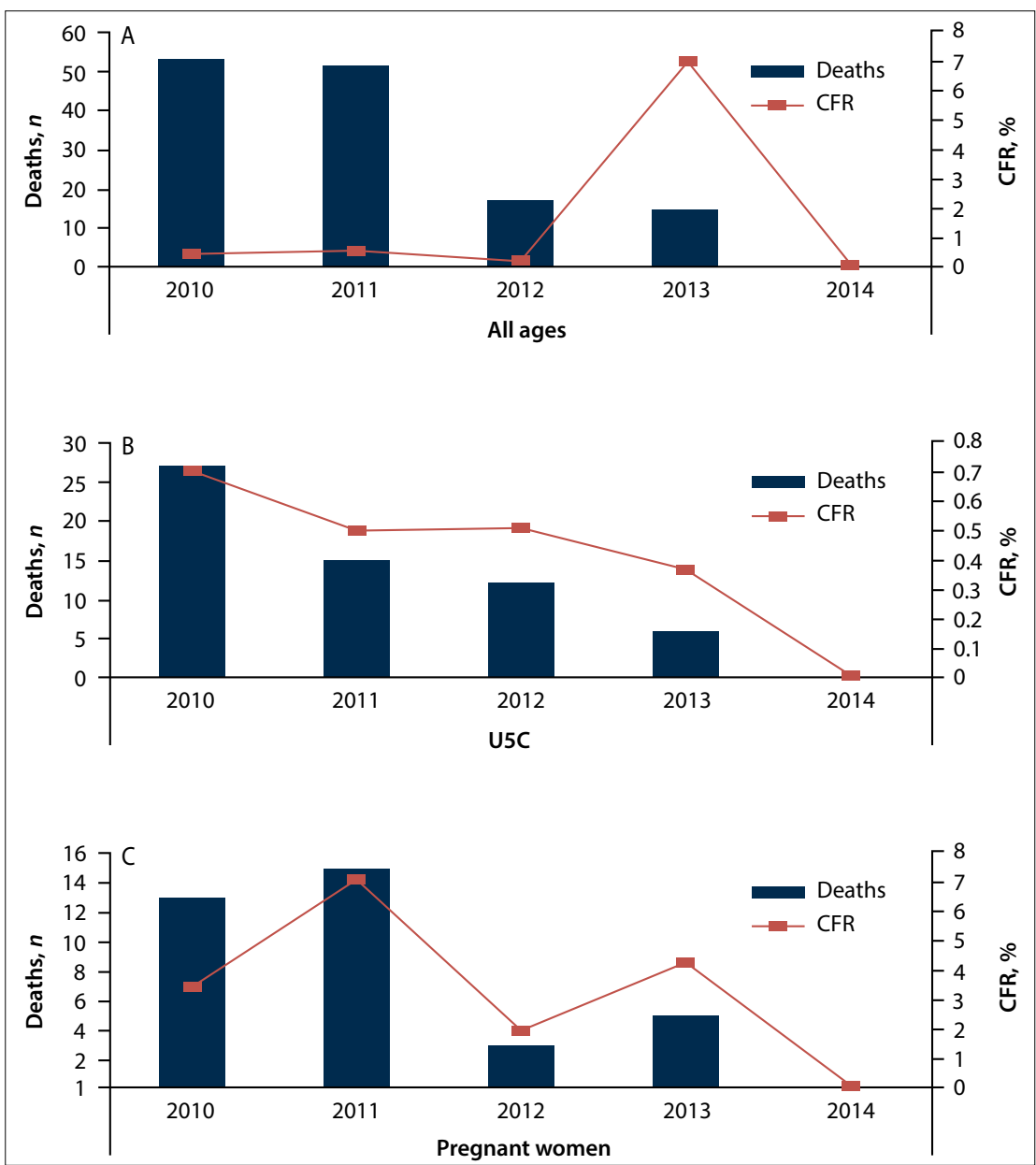

Fig. 2. Trends in malaria deaths and CFR between 2010 and 2014 for all ages (A), U5C (B) and pregnant women (C).

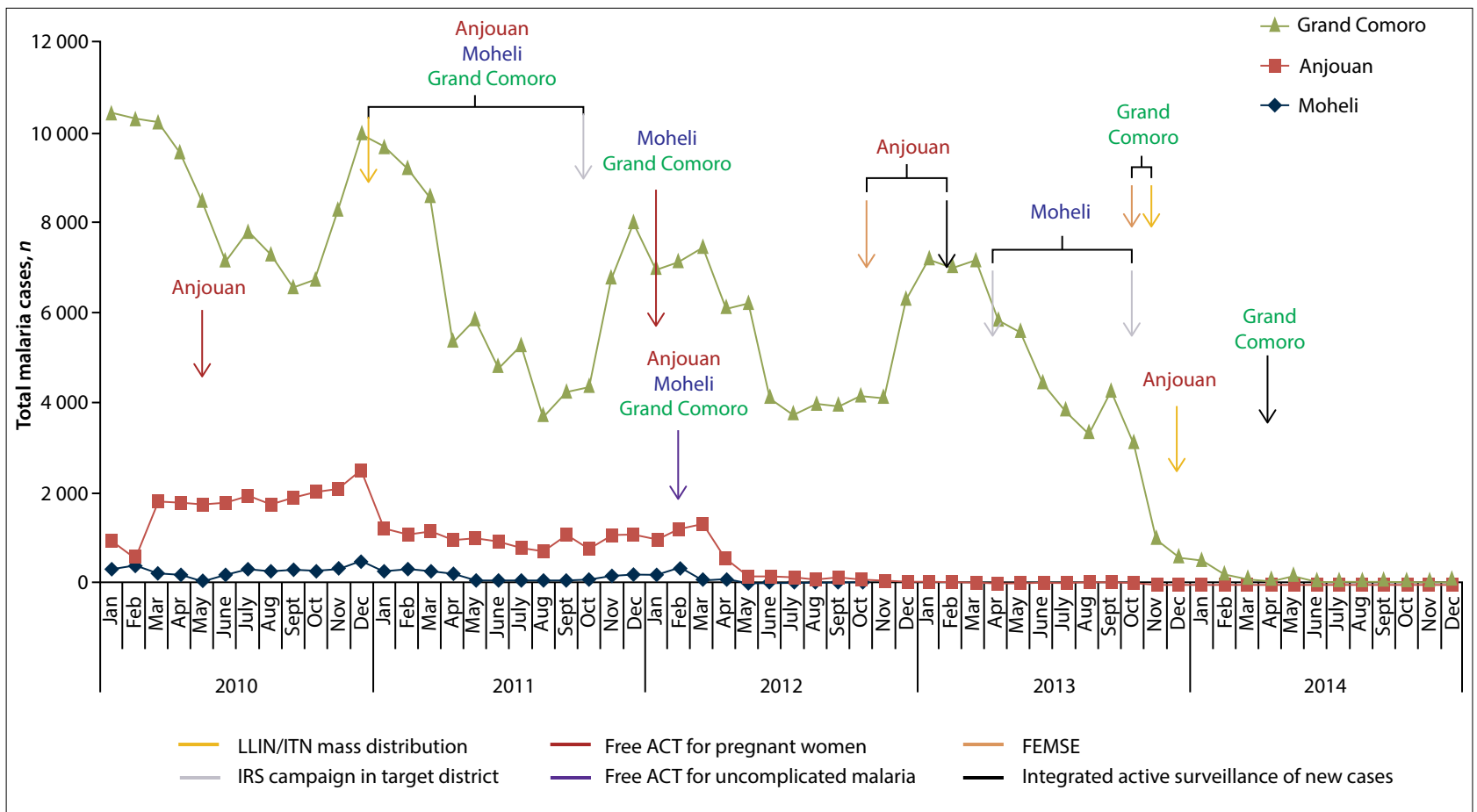

Fig. 3. Trends in number of malaria cases by month and year in the three islands of Moheli, Anjouan and Grand Comoro in relation to implementation of the malaria policy and interventions. 
Grand Comoro has a high population density compared with the other two. Another possible reason for the observed difference is that inhabitants of Grand Comoro experience more mosquito bites per day than inhabitants of the other two islands. ${ }^{[6,24]}$

For the period under review, there were no reported deaths for all age groups in Moheli, unlike Anjouan and Grand Comoro (Table 1). This observed difference may be related to the FEMSE intervention implemented in 2007, in conjunction with other interventions such as IRS and the distribution of LLINs, which continued in subsequent years. These interventions, especially the FEMSE, were reported to have contributed to a significant reduction in parasite carriage rate. ${ }^{[12]}$ Additionally, free access to ACT for the general population and sulfadoxine-pyrimethamine for pregnant women was made possible by the government with support from its international partners in Moheli in the years after the implementation of the FEMSE programme.

Comparing Figs 1 and 2, we see a general decline in malaria incidence and case fatalities for all ages, including pregnant women and U5C, in all three islands from 2010 to 2014. The implementation of a cocktail of interventions at different times during the study period resulted in zero malaria incidence and case fatalities at the end of 2014. Fig. 3 gives a detailed picture of the effect of each malaria intervention on the overall reduction of malaria morbidity and mortality observed in this study. For instance, the mass distribution of LLINs in all three islands in November 2010, and in December 2013 in Anjouan, was followed by a subsequent reduction in malaria cases for all three islands. Similar patterns were observed with mass administration of ACT and the FEMSE intervention. However, it is worth noting that zero malaria deaths were recorded in Anjouan and Grand Comoro after the FEMSE intervention was implemented in 2012 and 2013 respectively (Table 1). This shows that the FEMSE programme contributed to overall malaria morbidity and mortality and is in line with the results of similar studies conducted in countries in Asia. ${ }^{[13]}$

As mentioned earlier, this study was the first of its kind that attempted to observe trends in malaria morbidity and mortality since the WHO malaria guidelines were implemented in the three main islands of Comoros in 2010. However, it has some limitations. The study fails to look at the effect of each intervention on malaria morbidity and mortality in all three islands. Furthermore, sex distribution of malaria cases and deaths, as well as the influence of climatic conditions, especially rainfall pattern, on malaria morbidity and mortality for all three islands were not presented as aggregate data as these variables were not available from the national malaria control programme and meteorological department at the time of conducting this research. Future studies are recommended to address these gaps.

\section{Conclusion}

This study demonstrated the significant reduction in malaria morbidity and mortality in the islands of Moheli, Anjouan and Grand Comoro from 2010 to 2014. This was due to a combination of malaria control interventions implemented during the study period. Future studies should focus on the extent to which each intervention contributed to the reduction in malaria morbidity and mortality.

\section{References}

1. World Health Organization. Fact sheet on the World Malaria Report 2014. Geneva: WHO, 2015. http:// www.who.int/malaria/media/world_malaria_report_2014/en/ (accessed 23 October 2015).

2. Snow RW, Kibuchi E, Karuri SW, et al. Changing malaria prevalence on the Kenyan Coast since 1974: Climate, drugs and vector control. PloS One 2015;10(6):e0128792. DOI:10.1371/journal.pone.0128792

3. Parham PE, Michael E. Modeling the effects of weather and climate change on malaria transmission. Environ Health Perspect 2010;118(5):620-626. DOI:10.1289/ehp.0901256

4. World Health Organization. World Malaria Report 2014. Geneva: WHO, 2014.

5. United Nations. World Statistics Pocketbook. New York: UN, 2014. http://unstats.un.org/unsd/ pocketbook/WSPB2014.pdf (accessed 10 June 2015).

6. Rebaudet S, Bogreau H, Silai R, et al. Genetic structure of Plasmodium falciparum and elimination of malaria, Comoros Archipelago. Emerg Infect Dis 2010;16(11):1686-1694. DOI:10.3201/eid1611.100694

7. Silai R, Moussa M, Mari MA, et al. Surveillance of falciparum malaria susceptibility to antimalarial drugs and policy change in the Comoros. Bull Soc Pathol Exot 2007;100(1):6-9.

8. Mukonoweshuro EG. The politics of squalor and dependency: Chronic political instability and 8. Mukonoweshuro EG. The politics of squalor and dependency: Chronic
economic collapse in the Comoro Islands. Afr Affairs 1990;89(357):555-577.

9. African Development Bank Group, United Nations Development Programme and United Nations
economic collapse in the Comoro Islands. Afr Aftais 1990;8(357):55-577. Economic Commission for Africa. Africa Economic Outlook: Africa and Its Emerging Partners. OECD, UNDP and UNECA, 2011

10. Comoros Malaria Control Programme, Ministry of Health. National Malaria Report. Grand Comoro Malaria Control Program, 2013.

11. Secretariat General du Gouvernement Commissariat General au Plan, Direction Générale de la Statistique et de la Prospective (DGSP) Moroni, Comores et ICF International. Enquête Démographique et de Santé et à Indicateurs Multiples (EDSC-MICS II) 2012. Rockville, USA: ICF International, 2014. http://dhsprogram.com/publications/publication-FR278-DHS-Final-Reports.cfm (accessed 28 June 2016).

12. Deng $\mathrm{C}$, Wang $\mathrm{Q}$, Zheng $\mathrm{S}$, et al. Mass drug administration of artemisinin-piperaquine on high malaria epidemic area. Trop Med Health 2014;42(2Suppl):33-41. DOI:10.2149/tmh.2014-S05

13. Song J, Socheat D, Tan B, et al. Rapid and effective malaria control in Cambodia through mass . Song J, Socheat D, Tan B, et al. Rapid and effective malaria control in Cambodia through
administration of artemisinin-piperaquine. Malaria J 2010;9(1):57. DOI:10.1186/1475-2875-9-57

4. Newby G, Hwang J, Koita K, et al. Review of mass drug administration for malaria and its operational Newby G, Hwang J, Koita K, et al. Review of mass drug administration for malaria
challenges. Am J Trop Med Hyg 2015;93(1):125-134. DOI:10.4269/ajtmh.14-0254

15. Alonso PL, Tanner M. Public health challenges and prospects for malaria control and elimination. Nat Med 2013;19(2):150-155

16. Maillard O, Lernout T, Olivier S, et al. Major decrease in malaria transmission on Mayotte Island. Malaria J 2015;14(1):323. DOI:10.1186/s12936-015-0837-6

17. Mmbando BP, Vestergaard LS, Kitua AY, Lemnge MM, Theander TG, Lusingu JP. A progressive declining in the burden of malaria in north-eastern Tanzania. Malaria J 2010;9(1):216. DOI:10.1186/1475-2875-9-216

18. Karema C, Aregawi MW, Rukundo A, et al. Trends in malaria cases, hospital admissions and deaths following scale-up of anti-malarial interventions, 2000 - 2010, Rwanda. Malaria J 2012;11(1):236. DOI:10.1186/1475-2875-11-236

19. Landoh ED, Tchamdja P, Saka B, et al. Morbidity and mortality due to malaria in Est Mono district, Togo, from 2005 to 2010: A times series analysis. Malaria J 2012;11(1):389. DOI:10.1186/1475-2875-11-389

20. United Nations. Country Profile: Comoros. Geneva: UN, 2015. http://data.un.org/CountryProfile, anited Nations. Country Profile: Comoros. Genev:
aspx? crName=comoros (accessed 29 October 2015).

21. World Health Organization. Guidelines for the Treatment of Malaria. Geneva: WHO, 2015 .

21. World Health Organization. Guidelines for the Treatment of Malaria. Geneva: WHO, 2015.
22. World Health Organization. Country Cooperation Strategy - At a Glance: Comoros. Geneva: WHO, 2014. https://extranet.who.int/iris/restricted/bitstream/10665/137153/1/ccsbrief_com_en.pdf (accessed 27
(1) Corld Health Organization. Country Cooperation Strategy - At a Glance: Comoros. Geneva: WHO, October 2015).

23. Ngomane L, de Jager C. Changes in malaria morbidity and mortality in Mpumalanga Province, South Africa (2001 - 2009): A retrospective study. Malaria J 2012;11(1):19. DOI:10.1186/1475-2875-11-19.

24. Blanchy S, Julvez J, Mouchet J. Stratification épidémiologique du paludisme dans larchipel des Comores. Bull Soc Pathol Exot 1999;92(3):177-184.

Accepted 21 April 2016. 